\title{
ARTICLE
}

Multiple myeloma gammopathies

\section{Characterisation of immunoparesis in newly diagnosed myeloma and its impact on progression-free and overall survival in both old and recent myeloma trials}

\author{
Jennifer L. J. Heaney ${ }^{1} \cdot$ John P. Campbell ${ }^{1,2} \cdot$ Gulnaz Iqbal $^{3} \cdot{\text { David Cairns } \mathbb{D}^{4} \cdot \text { Alex Richter }^{1} \cdot \text { J. Anthony Child }}^{4}$. \\ Walter Gregory ${ }^{4} \cdot$ Graham Jackson $^{5} \cdot$ Martin Kaiser $^{6} \cdot$ Roger Owen $^{7} \cdot$ Faith Davies $^{8} \cdot$ Gareth Morgan $^{8} \cdot$ Janet Dunn $^{3}$. \\ Mark T. Drayson ${ }^{1}$
}

Received: 11 December 2017 / Revised: 27 March 2018 / Accepted: 27 April 2018 / Published online: 20 June 2018

(c) The Author(s) 2018. This article is published with open access

\begin{abstract}
We measured immunosuppression at myeloma diagnosis and assessed the impact on survival in 5826 UK myeloma trial patients. Polyclonal immunoglobulin levels were below normal in $85 \%$ of patients and above normal in only $0.4 \%$ of cases for IgA, $0.2 \%$ for IgM and no cases for IgG. Immunoparesis had a greater impact in recent trials: median overall survival (OS) was up to 3 years longer for patients without immunoparesis compared to the old trials, less than 1 year longer. Median progression-free survival (PFS) was 39\%, 36\% and 57\% longer for patients with normal IgG, IgA and IgM levels, respectively. The depth of IgM suppression, but not the depth of IgG or IgA suppression, was prognostic for survival: the most severely suppressed IgM tertile of patients OS was 0.9 years shorter than those in the top tertile, and 2.6 years shorter than OS of those with normal IgM levels $(p=.007)$. The degree of suppression of polyclonal IgM levels below normal was associated with worse PFS $(p=.0002)$. Infection does not appear to be the main mechanism through which immunoparesis affects survival. We hypothesise that IgM immunoparesis impacts through a combination of being associated with more aggressive disease and reduced immune surveillance against relapse.
\end{abstract}

These authors contributed equally: Jennifer L. J. Heaney,

John P. Campbell.

Electronic supplementary material The online version of this article (https://doi.org/10.1038/s41375-018-0163-4) contains supplementary material, which is available to authorised users.

Mark T. Drayson

M.T.Drayson@bham.ac.uk

1 Institute of Immunology and Immunotherapy, University of Birmingham, Birmingham, UK

2 University of Bath, Bath, UK

3 University of Warwick, Warwick, UK

4 University of Leeds, Leeds, UK

5 University of Newcastle, Newcastle, UK

6 Institute of Cancer Research, London, UK

7 St James's University Hospital, Leeds, UK

8 University of Arkansas for Medical Sciences, Little Rock, AR, USA

\section{Introduction}

Multiple myeloma (MM) is an incurable neoplastic disorder that arises from the proliferation of a single clone of plasma cells in the bone marrow and accounts for over $10 \%$ of haematological malignancies [1, 2]. An established feature of $\mathrm{MM}$ is suppression of the adaptive immune system and resultant low levels of polyclonal antibodies (immunoparesis) [3-8]. This $\mathrm{T}$ and $\mathrm{B}$ lymphocyte immunosuppression increases the susceptibility to both bacterial and viral infections, and the antibody levels have been shown to be significantly lower in myeloma patients who experienced serious infections [9-11]. Infection is a major cause of morbidity and mortality in myeloma patients, particularly in the first 3 months from diagnosis [10, 12, 13], with immunoparesis, a contributory factor to this that we are currently investigating in a UK trial of antibiotic prophylaxis (TEAMM). Less attention has been given to longerterm outcomes and the hypotheses, that increasing depth of immunosuppression is a result of more aggressive MM (thus a marker of poor prognosis) and separately that 
immunosuppression renders MM more likely to progress because of the reduced immune surveillance.

Immunoparesis and an associated increased risk of progression to active MM occurs in 20\% of MGUS patients and $70 \%$ of smouldering MM [14 -17]. In active MM prevalence, low antibodies increased from $63 \%$ in Durie-Salmon stage I to $90 \%$ in stage III [4]. This was also found in a recent registry-based study in 1755 consecutive myeloma patients over 22 years to 2012, available through the Greek Myeloma Study Group [18]. At least one isotype was suppressed in $77 \%$ versus $88 \%$ versus $94 \%$ of patients with International Staging System-1, -2 and -3 disease, respectively. Preservation of the uninvolved immunoglobulins was found in $13 \%$ of patients, which was associated with significantly longer overall survival. This study did not include clinical trial patients, but in a subset of 500 patients, there was sufficient follow-up data to assess progression-free survival, which was longer for patients with normal polyclonal antibody levels. This group found immunoparesis commoner in patients with IgA MM, while a previous study found immunoparesis commoner in IgG MM [5]. These studies did not compare the depths of immunoparesis for different antibody isotypes, which may be important, given the different anatomical sites of normal plasma cells secreting polyclonal IgM (lymph nodes and spleen) versus IgG and IgA (bone marrow). In addition, previous studies have not investigated the significance of suppression of the alternate polyclonal free light chain. Thus, there remains a need to investigate the significance of the depth and character of immunoparesis in the context of modern anti-myeloma therapy with detailed longterm survival outcomes to explore the potential consequences of increased risk of infection, reduced tumour surveillance and association with poor prognosis of MM.

To further characterise the prevalence and severity of immunoparesis at diagnosis and the prognostic significance for overall survival (OS) and progression-free survival (PFS), we have retrospectively analysed data from a large cohort of 3247 newly diagnosed MM patients enroled in the Myeloma IX and Myeloma XI clinical trials. To compare the impact of immunoparesis on survival outcomes between modern anti-myeloma therapy and pre-biological treatment regimes, we also assessed the relationship between immunoparesis and survival in 2807 patients from the MRC myeloma trials from 1980 to 1997, prior to the establishment of novel agents and the benefit of intensive therapy.

\section{Methods}

\section{Patients and clinical trials}

Patients were enroled in either the MRC Myeloma IX (MIX) trial (ISRCTN68454111) or the Cancer Research UK
Myeloma XI (MXI) trial (ISRCTN49407852), and henceforth will be referred to as the 'recent myeloma trials'. In these multicentre, phase III trials, newly diagnosed patients were divided between an intensive and a non-intensive pathway based on their eligibility for the autologous stem cell transplantation and assessed in relation to progression-free and overall survival (PFS and OS). MIX randomised to receive thalidomide versus non-thalidomide-containing therapy, thalidomide could be given both as an induction and/or as a maintenance regimen [19-22]. MXI compares lenalidomide with thalidomide induction therapies and assesses the value of bortezomib in poor responders. In remission, patients are randomised to no maintenance or to receive lenalidomide, or lenalidomide-vorinostat maintenance therapy. Data were available for 3247 patients from MIX and MXI (up to a randomisation date of 1 June 2013 to allow for sufficient patient follow-up). However, only the data on 3218 out of the 3247 patients, where polyclonal IgM was recorded as part of the central laboratory immunochemistry analysis, were included in the patient characteristics table and multivariate analysis. To compare these trials using current anti-myeloma therapy to trials pre-dating novel biological agents, data were included from 2807 patients who enroled in MRC myeloma trials (MIV, MV, MVI and MVIII) from 1980 to 1997, henceforth referred to as the 'old' myeloma trials. Treatment allocation within these trials has been described previously [23]. The patient characteristics table and multivariate analysis were performed on 2608 of 2807 patients, where IgM levels were recorded. Multicentre research ethics committees and local ethics committees approved all the trials, and all patients gave written informed consent.

\section{Measures and patient classification}

Serum from diagnosis was analysed centrally by protein electrophoresis, densitometry and immunofixation for Mprotein quantification and characterisation. Serum IgG, IgA and IgM, and kappa and lambda free light chains (sFLC) levels were quantified by turbidimetry. Patients were characterised as having one of the following multiple myelomas: IgG, IgA, IgM, IgD, light chain only (LCO), non-secretory (NS) or oligosecretory; with either kappa or lambda monoclonal light chain. Patients were classified as being below, within or above normal range (NR) for polyclonal immunoglobulins based upon 5th-95th centile ranges of adults aged over 45 years in the UK reported by PRU (Protein Reference Units): IgG 6-16 g/L; IgA $0.8-4 \mathrm{~g} / \mathrm{L}$; and IgM $0.5-2 \mathrm{~g} / \mathrm{L}$. For sFLC levels, patients were classified as being above, within or below NR $(3.3-19.4 \mathrm{mg} / \mathrm{L}$ for lambda and 5.7-26.3 mg/L for kappa) [24].

Patients were classified into two groups according to the presence or absence of adverse cytogenetic abnormalities: standard risk (no adverse cytogenetic abnormalities) and 
Table 1 Characterisation of patients included in the present analyses by immunoparesis of polyclonal IgM (within normal range versus below normal range) from those enroled in MRC myeloma trials from 1980 to 1997 (old trials) compared to the MRC Myeloma IX trial (2003-2008) and the ongoing NCRI Myeloma XI trial (2010-2016)

\begin{tabular}{|c|c|c|c|c|c|c|c|c|c|}
\hline \multirow[b]{2}{*}{ Factor } & \multirow[b]{2}{*}{ Grouping } & \multicolumn{3}{|c|}{ Old trials (MIV, MV, MVI and MVIII) } & \multirow[b]{2}{*}{$p$} & \multicolumn{3}{|c|}{ Recent trials (MIX and MXI) } & \multirow[b]{2}{*}{$p$} \\
\hline & & $\begin{array}{l}\text { IgM within } \\
\text { NR } \\
N=535\end{array}$ & $\begin{array}{l}\text { IgM below } \\
\text { NR } \\
N=2073\end{array}$ & $\begin{array}{l}\text { Total } \\
N=2608\end{array}$ & & $\begin{array}{l}\text { IgM within } \\
\text { NR } \\
N=348\end{array}$ & $\begin{array}{l}\text { IgM below } \\
\text { NR } \\
N=2870\end{array}$ & $\begin{array}{l}\text { Total } \\
N=3218\end{array}$ & \\
\hline \multirow[t]{2}{*}{ Gender } & Male & $298(56 \%)$ & $1196(58 \%)$ & $\begin{array}{l}1494 \\
(57 \%)\end{array}$ & .45 & $198(58 \%)$ & $1645(59 \%)$ & $\begin{array}{l}1843 \\
(59 \%)\end{array}$ & .77 \\
\hline & Female & $236(44 \%)$ & $876(42 \%)$ & $\begin{array}{l}1112 \\
(43 \%)\end{array}$ & & $144(42 \%)$ & $1148(41 \%)$ & $\begin{array}{l}1292 \\
(41 \%)\end{array}$ & \\
\hline \multirow[t]{2}{*}{ Age group } & $<65$ years & $287(54 \%)$ & $1018(49 \%)$ & $\begin{array}{l}1305 \\
(50 \%)\end{array}$ & .07 & $169(49 \%)$ & $1226(43 \%)$ & $\begin{array}{l}1395 \\
(44 \%)\end{array}$ & .05 \\
\hline & $\geq 65$ years & $248(46 \%)$ & $1051(51 \%)$ & $\begin{array}{l}1299 \\
(50 \%)\end{array}$ & & $179(51 \%)$ & $1632(57 \%)$ & $\begin{array}{l}1811 \\
(56 \%)\end{array}$ & \\
\hline \multirow[t]{2}{*}{ Pathway } & Intensive & - & - & - & - & $210(60 \%)$ & $1627(57 \%)$ & $\begin{array}{l}1837 \\
(57 \%)\end{array}$ & .21 \\
\hline & Non-intensive & - & - & - & - & $138(40 \%)$ & $1243(43 \%)$ & $\begin{array}{l}1381 \\
(43 \%)\end{array}$ & \\
\hline \multirow[t]{7}{*}{ M-protein type } & $\operatorname{IgG}$ & $343(64 \%)$ & $1131(55 \%)$ & $\begin{array}{l}1474 \\
(56 \%)\end{array}$ & .001 & $231(66 \%)$ & $1700(59 \%)$ & $\begin{array}{l}1931 \\
(60 \%)\end{array}$ & .002 \\
\hline & $\operatorname{IgA}$ & $123(23 \%)$ & $580(28 \%)$ & $703(27 \%)$ & & $60(17 \%)$ & $708(25 \%)$ & $768(24 \%)$ & \\
\hline & $\operatorname{IgD}$ & $4(1 \%)$ & $36(2 \%)$ & $40(2 \%)$ & & $4(1 \%)$ & $51(2 \%)$ & $55(2 \%)$ & \\
\hline & $\operatorname{IgE}$ & $1(<1)$ & $1(<1)$ & $2(<1 \%)$ & & - & - & - & \\
\hline & Light chain only & $55(10 \%)$ & $296(14 \%)$ & $351(13 \%)$ & & $43(12 \%)$ & $370(13 \%)$ & $413(13 \%)$ & \\
\hline & Non-secretory & $9(2 \%)$ & $29(1 \%)$ & $38(1 \%)$ & & $7(2 \%)$ & $17(1 \%)$ & $24(1 \%)$ & \\
\hline & Oligosecretory & - & - & - & & $3(1 \%)$ & $24(1 \%)$ & $27(1 \%)$ & \\
\hline \multirow[t]{3}{*}{$\% \mathrm{BMPCs}$} & $<20$ & $152(40 \%)$ & $331(21 \%)$ & $483(24 \%)$ & $<.0001$ & $189(61 \%)$ & $774(29 \%)$ & $963(32 \%)$ & $<.0001$ \\
\hline & $20-50$ & $156(41 \%)$ & $724(45 \%)$ & $880(44 \%)$ & & $99(32 \%)$ & $1182(45 \%)$ & $\begin{array}{l}1281 \\
(43 \%)\end{array}$ & \\
\hline & $>50$ & $76(20 \%)$ & $559(35 \%)$ & $635(32 \%)$ & & $23(7 \%)$ & $699(26 \%)$ & $722(24 \%)$ & \\
\hline \multirow[t]{3}{*}{$\mathrm{Sb} 2 \mathrm{~m}(\mathrm{mg} / \mathrm{l})$} & $\leq 4$ & $208(40 \%)$ & $460(23 \%)$ & $668(26 \%)$ & $<.0001$ & $235(68 \%)$ & $1317(46 \%)$ & $\begin{array}{l}1552 \\
(48 \%)\end{array}$ & $<.0001$ \\
\hline & $4-8$ & $195(37 \%)$ & $807(40 \%)$ & $\begin{array}{l}1002 \\
(39 \%)\end{array}$ & & $89(26 \%)$ & $1069(37 \%)$ & $\begin{array}{l}1158 \\
(36 \%)\end{array}$ & \\
\hline & $>8$ & $117(23 \%)$ & $765(38 \%)$ & $822(35 \%)$ & & $23(6 \%)$ & $480(17 \%)$ & $503(16 \%)$ & \\
\hline \multirow[t]{3}{*}{ Albumin (g/l) } & $<30$ & $79(22 \%)$ & $458(29 \%)$ & $537(27 \%)$ & .001 & $55(17 \%)$ & $559(20 \%)$ & $614(20 \%)$ & .008 \\
\hline & $30-35$ & $106(30 \%)$ & $535(33 \%)$ & $641(33 \%)$ & & $81(24 \%)$ & $846(30 \%)$ & $927(30 \%)$ & \\
\hline & $>35$ & $174(48 \%)$ & $612(38 \%)$ & $786(40 \%)$ & & $195(59 \%)$ & $1397(50 \%)$ & $\begin{array}{l}1592 \\
(51 \%)\end{array}$ & \\
\hline \multirow[t]{3}{*}{ eGFR $\mathrm{ml} / \mathrm{min}$} & $<30$ & $89(17 \%)$ & $453(22 \%)$ & $542(21 \%)$ & .0003 & $19(6 \%)$ & $287(10 \%)$ & $306(10 \%)$ & .008 \\
\hline & $30-60$ & $230(43 \%)$ & $961(46 \%)$ & $\begin{array}{l}1191 \\
(46 \%)\end{array}$ & & $116(34 \%)$ & $995(36 \%)$ & $\begin{array}{l}1111 \\
(35 \%)\end{array}$ & \\
\hline & $>60$ & $215(40 \%)$ & $654(32 \%)$ & $869(33 \%)$ & & $207(60 \%)$ & $1502(54 \%)$ & $\begin{array}{l}1709 \\
(55 \%)\end{array}$ & \\
\hline \multirow[t]{3}{*}{ ISS } & I & $81(17 \%)$ & $146(7 \%)$ & $227(9 \%)$ & $<.0001$ & $134(41 \%)$ & $608(22 \%)$ & $742(24 \%)$ & $<.0001$ \\
\hline & II & $169(36 \%)$ & $617(32 \%)$ & $786(33 \%)$ & & $128(39 \%)$ & $1086(40 \%)$ & $\begin{array}{l}1214 \\
(40 \%)\end{array}$ & \\
\hline & III & $214(46 \%)$ & $1189(61 \%)$ & $\begin{array}{l}1403 \\
(58 \%)\end{array}$ & & $67(20 \%)$ & $1024(38 \%)$ & $\begin{array}{l}1091 \\
(36 \%)\end{array}$ & \\
\hline \multirow[t]{2}{*}{ LDH IU/L } & $<273$ & - & - & - & & $92(36 \%)$ & $892(42 \%)$ & $984(41 \%)$ & .07 \\
\hline & $\geq 273$ & - & - & - & & $163(64 \%)$ & $1224(58 \%)$ & $\begin{array}{l}1387 \\
(59 \%)\end{array}$ & \\
\hline
\end{tabular}


Table 1 (continued)

\begin{tabular}{|c|c|c|c|c|c|c|c|c|c|}
\hline \multirow[b]{2}{*}{ Factor } & \multirow[b]{2}{*}{ Grouping } & \multicolumn{3}{|c|}{ Old trials (MIV, MV, MVI and MVIII) } & \multirow[b]{2}{*}{$p$} & \multicolumn{3}{|c|}{ Recent trials (MIX and MXI) } & \multirow[b]{2}{*}{$p$} \\
\hline & & $\begin{array}{l}\text { IgM within } \\
\text { NR } \\
N=535\end{array}$ & $\begin{array}{l}\text { IgM below } \\
\text { NR } \\
N=2073\end{array}$ & $\begin{array}{l}\text { Total } \\
N=2608\end{array}$ & & $\begin{array}{l}\text { IgM within } \\
\text { NR } \\
N=348\end{array}$ & $\begin{array}{l}\text { IgM below } \\
\text { NR } \\
N=2870\end{array}$ & $\begin{array}{l}\text { Total } \\
N=3218\end{array}$ & \\
\hline \multirow[t]{3}{*}{ Genetic risk } & Standard risk & - & - & - & & $115(33 \%)$ & $798(28 \%)$ & $913(28 \%)$ & \multirow[t]{3}{*}{$<.0001^{\mathrm{a}}$} \\
\hline & High risk & - & - & - & & $43(12 \%)$ & $694(24 \%)$ & $737(23 \%)$ & \\
\hline & Unknown & & & & & $190(55 \%)$ & $1378(48 \%)$ & $\begin{array}{l}1568 \\
(49 \%)\end{array}$ & \\
\hline
\end{tabular}

${ }^{\mathrm{a}}$ Test is based on those with a result only

high risk (one or more adverse cytogenetic abnormalities). Adverse cytogenetic abnormalities were defined as gain (1q), $\mathrm{t}(4 ; 14), \mathrm{t}(14 ; 16), \mathrm{t}(14 ; 20)$ or $\operatorname{del}(17 \mathrm{p})[22,25]$.

\section{Statistical analyses}

Immunoparesis at diagnosis was assessed for patients in MIX and MXI trials. Mann-Whitney $U$-tests and Kruskal-Wallis tests were used for comparisons between M-protein groups and kappa and lambda myelomas, as appropriate. Spearman's rank correlations were performed to evaluate the relationships between M-protein and polyclonal immunoglobulins, and sFLC. Data were analysed using IBM SPSS statistics version 21.

Patient characteristics are presented for old and recent myeloma trials by polyclonal IgM (within NR, below NR). Differences in patient characteristics were investigated using the Pearson's $\chi^{2}$-test with continuity adjustment used wherever appropriate. Survival curves were constructed using the method of Kaplan and Meier, and the log-rank test was used to assess the differences between the groups, in the old myeloma trials and recent myeloma trials [26, 27]. OS was defined as 'date of entry to the trial' to 'date of death' or censored at 'last alive date'. PFS was defined as time from date of entry to progression or death, or censored at date last known to be alive and progression free. Progression was defined as relapse from complete response, if one was achieved or documented progressive disease [28]. Survival outcomes were analysed between patients who were below or within the NR for polyclonal immunoglobulins and FLCs, and assessed based on the degree of immunoparesis. Degree of immunoparesis was obtained by splitting the patients who were below the NR into three groups for $\operatorname{IgG}, \operatorname{Ig}$ A and $\operatorname{IgM}$ individually. Cox regression was performed to determine whether polyclonal IgM was an independent predictor of OS and PFS after adjusting for S $\beta 2 \mathrm{M}, \mathrm{BMPCs}$ and ISS in the old trials, with the addition of LDH and genetic risk in the recent trials [29]. Survival analysis and Cox regression were performed using SAS statistical software (SAS Institute, SAS Circle, Cary, NC, USA).

\section{Results}

\section{Patient characteristics}

The study included 2608 patients older MRC trials $(21 \%$ with polyclonal IgM within NR and $79 \%$ with polyclonal IgM below NR) all receiving conventional therapy as described previously, Table 1 [23]; and 3218 patients from recent trials (11\% with polyclonal IgM within NR and $89 \%$ with polyclonal IgM below NR). The proportion of patients aged $\geq 65$ years increased from $50 \%$ in the old trials to $56 \%$ in recent trials, reflecting an increase in patients $\geq 65$ years receiving intensive therapy. Twenty-four per cent of patients were ISS stage I in recent trials compared to $9 \%$ in older trials reflecting improvements in diagnosis.

Comparison of factors between groups with $\operatorname{IgM}$ within the NR and IgM below the NR in the older trials and recent trials demonstrated an increase in BMPCs and S $\beta 2 \mathrm{M}$ in IgM below NR groups compared to the within NR group, $p<.0001$, Table 1. Albumin was higher, where IgM was within the NR in both old and recent trials $(p=.001$ and $p$ $=.008$, respectively). $\mathrm{LDH}$ recorded in the recent trials did not significantly differ between groups $(p=.07)$. Patients with lower IgM were more likely to have adverse cytogenetic abnormalities present compared to those with IgM within NR (24\% versus $12 \%, p=<.0001)$.

\section{Characterisation of immunoparesis}

Figure 1 illustrates the distribution of polyclonal $\operatorname{IgG}, \operatorname{IgA}$ and $\operatorname{IgM}$ levels in patients without an IgG, IgA or IgM Mprotein, respectively. IgM levels were below the NR in $89 \%$ of patients compared to $80 \%$ of patients for $\operatorname{IgG}$ and $\operatorname{IgA}$ levels. Median polyclonal levels (IQR) for $\operatorname{IgG}, \operatorname{Ig} A$ and IgM were 3.9 (2.7-5.6), $0.3(0.2-0.6)$ and $0.2(0.1-0.3) \mathrm{g} / \mathrm{L}$, respectively. These values represent a reduction below the median value of the NR of $65 \%$ for $\operatorname{IgG}, 87 \%$ for $\operatorname{IgA}$ and $84 \%$ for IgM. No patient without an IgG M-protein had an IgG level above the NR of $16 \mathrm{~g} / \mathrm{L}$. A small proportion of patients presented with $\operatorname{IgA}(0.4 \%)$ and $\operatorname{IgM}$ levels $(0.2 \%)$ 

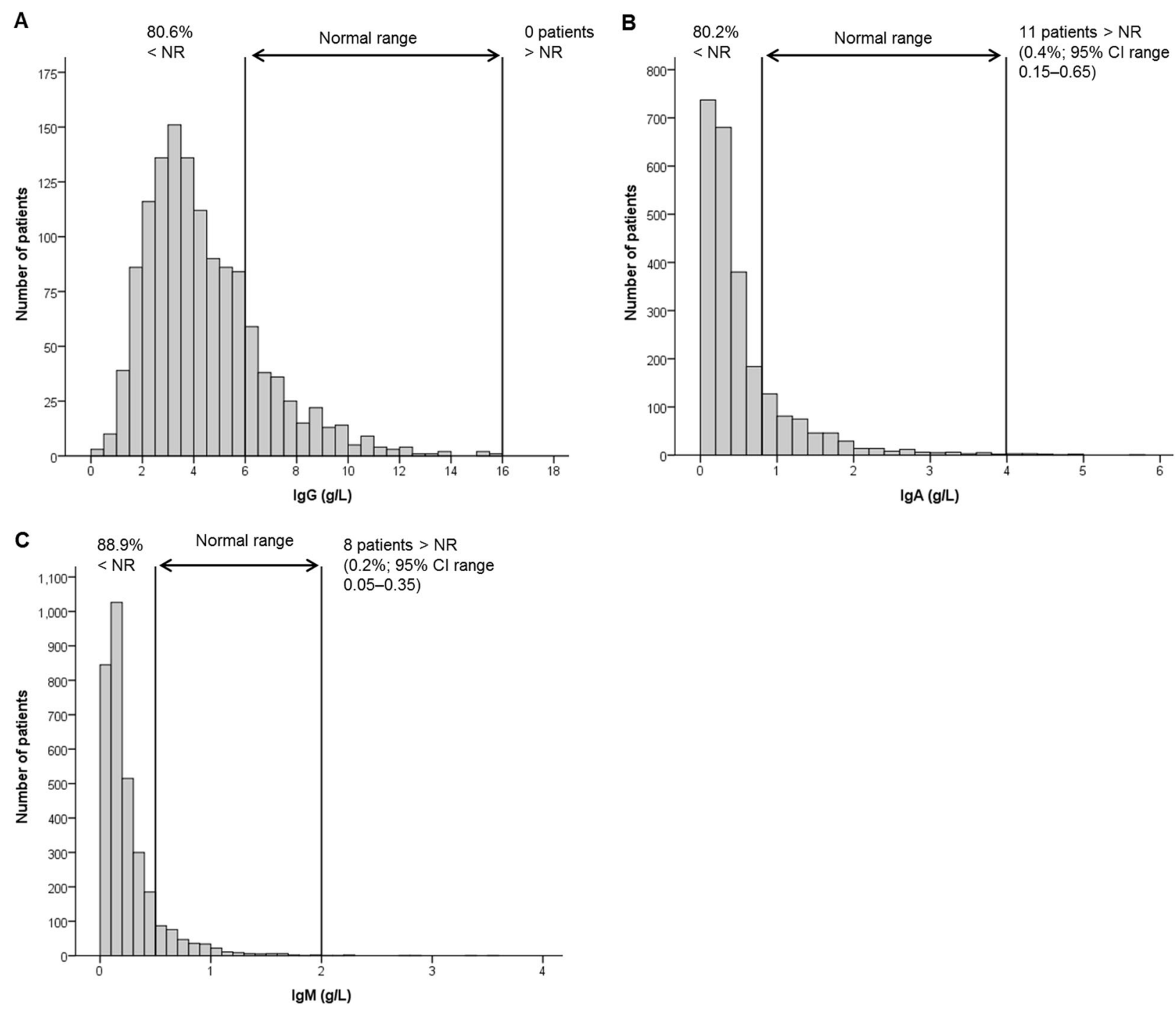

Fig. 1 Levels of polyclonal immunoglobulin in MIX and MXI clinical trials. Data are presented for levels of polyclonal $\operatorname{IgG}(\mathbf{a}, n=1302)$, $\operatorname{IgA}(\mathbf{b}, n=2469)$ and $\operatorname{IgM}(\mathbf{c}, n=3226)$ at disease presentation in all myeloma patients without an $\mathrm{IgG}$, IgA or IgM M-protein, respectively.

above the NR; median (IQR) concentrations in these patients were $4.4 \mathrm{~g} / \mathrm{L}(4.1-4.8 \mathrm{~g} / \mathrm{L})$ and $2.48 \mathrm{~g} / \mathrm{L}(2.1-3.2 \mathrm{~g} /$ $\mathrm{L})$, respectively. Individuals who were above the NR for IgA included five IgG patients, five LCO patients and one IgM patient. Patients who were above the NR for IgM comprised six $\operatorname{Ig} \mathrm{A}$ and two $\operatorname{IgG}$ patients.

\section{Immunoparesis by myeloma M-protein type}

Polyclonal immunoglobulin levels based on myeloma Mprotein type are presented in Fig. 2. Group differences in immunoparesis were evaluated between the three main patient M-protein groups (IgG, $\operatorname{IgA}$ and LCO) who together made up $95 \%$ of all patients. IgA patients had the most profound immunoparesis, followed by IgG and then LCO patients, but differences between the M-protein types,

For patients above normal ranges (NR), number of patients, percentage of patients and $95 \%$ confidence interval (CI) ranges for the percentage of patients are shown

although statistically significant, were not substantial (Fig. 2). Similarly, lambda patients demonstrated significantly but not substantially, lower polyclonal immunoglobulins across IgG, IgA and LCO patient groups (Supplementary Figure S1). Statistics were not performed for the remaining patient groups (IgD, IgM, NS and oligosecretory myeloma) due to small sample sizes; however, IgD patients had the lowest median polyclonal levels of all M-protein groups. This may be due to the high prevalence of lambda light chain type in IgD myeloma.

\section{Inverse relationship between $\mathrm{M}$-protein level and polyclonal immunoglobulin levels}

Higher M-protein levels were associated with significantly lower levels of polyclonal immunoglobulins. The strongest 
Fig. 2 Levels of polyclonal immunoglobulins by the three main patient M-protein subgroups in MIX and MXI. Statistics were performed for the three main patient groups with sufficient sample size (IgG, IgA and LCO). Significant differences between groups are indicated, $* * * p<0.001$. Dotted lines indicate the lower limit of the normal range of serum polyclonal immunoglobulin concentration: $6 \mathrm{~g} / \mathrm{L} \mathrm{IgG}, 0.8 \mathrm{~g} / \mathrm{L}$ $\mathrm{IgA}$ and $0.5 \mathrm{~g} / \mathrm{L} \mathrm{IgM}$

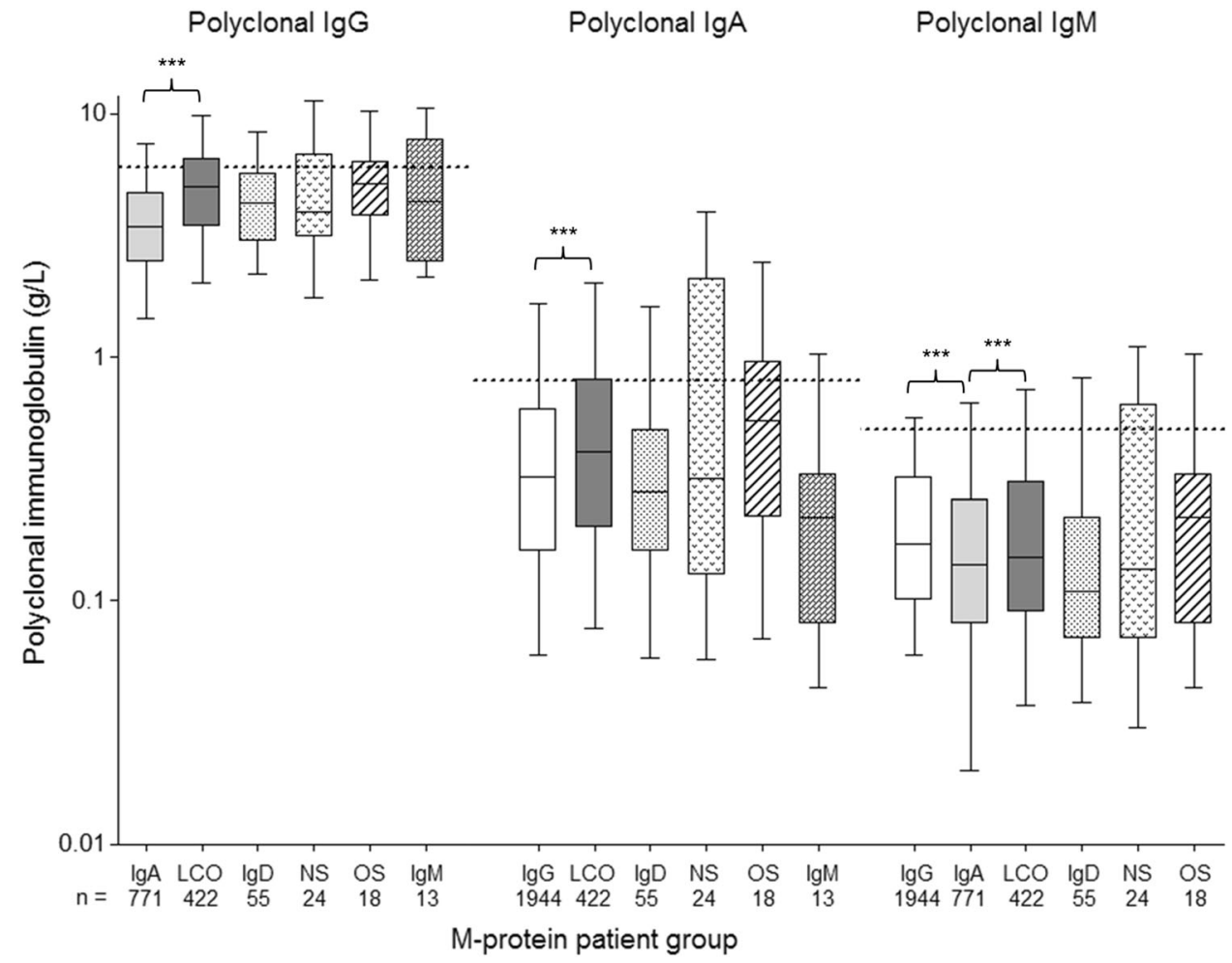

negative correlation was seen for IgA M-protein and polyclonal $\operatorname{IgG}\left(r_{\mathrm{s}}=-.414\right)$. The amount of IgA M-protein also negatively correlated with the level of polyclonal IgM, $r_{\mathrm{s}}=-.253$. In patients with IgG myeloma, negative relationships were also found between M-protein level and polyclonal $\operatorname{IgA}\left(r_{\mathrm{s}}=-.271\right)$ and $\operatorname{IgM}$ levels $\left(r_{\mathrm{s}}=-.254\right)$. These relationships are illustrated in Supplementary Figure $\mathrm{S} 2$ ( $p<0.001$ for all correlations).

\section{Inverse relationship between $\mathbf{M}$-protein level and polyclonal free light chain levels}

The level of polyclonal sFLC (uninvolved immunoglobulin) was inversely correlated with whole IgG or IgA M-protein level (Supplementary Figure S3, $p<0.05$ for all correlations). These plots of polyclonal sFLCs versus M-protein illustrate that Freelite did not identify polyclonal kappa sFLC levels between 2.5 and $5.5 \mathrm{mg} / \mathrm{L}$ and polyclonal lambda patients between 1.5 and $3.5 \mathrm{mg} / \mathrm{L}$. To overcome this problem, we analysed kappa and lambda sFLC levels in a sub-cohort of IgG and IgA patients using monoclonal antifree light chain reagents on a Luminex platform [30], which enabled a more sensitive assessment of the distribution of polyclonal sFLC levels without gaps in measurement (Supplementary Figure S4). These produced correlations of the same direction and strength compared to Freelite, with the exception of $\operatorname{IgA}$ lambda patients, where a stronger relationship was observed using Luminex data $\left(r_{\mathrm{s}}=-.406\right.$, $p=0.0001)$ compared to Freelite $\left(r_{\mathrm{s}}=-.126, p=0.03\right)$. As the assessment of polyclonal sFLC was more precise with the Luminex assay for measurement below the NR, we used the platform to later assess the relationship between sFLC immunoparesis and survival outcomes.

\section{Survival outcomes by M-protein type}

Survival data were available for 2587 patients from the old trials and 3109 from recent trials. Patients with IgG myeloma survived the longest in the old trials (median 2.52 years), followed by IgA myelomas (median 2.33 years) with LC-only myeloma patients doing worst (median 1.94 years, $p<.0001$, Supplementary Table 1). IgG patients continue to survive longest in recent trials and median OS has increased from 2.52 years in the old trials to 4.75 years. Light chain-only myeloma patients also benefited from increased OS (median 4.32 years in recent trials compared to 1.94 years in the old trials) and PFS (median 1.92 years in recent trials compared to 1.46 years in the older trials).

\section{Immunoparesis is associated with poorer survival outcomes}

Patients from the recent trials survived longer than patients from the old clinical trials, median OS 4.53 years $(95 \% \mathrm{CI}$ $=4.32-4.84)$ and 2.33 years $(95 \% \quad \mathrm{CI}=2.23-2.46)$, 


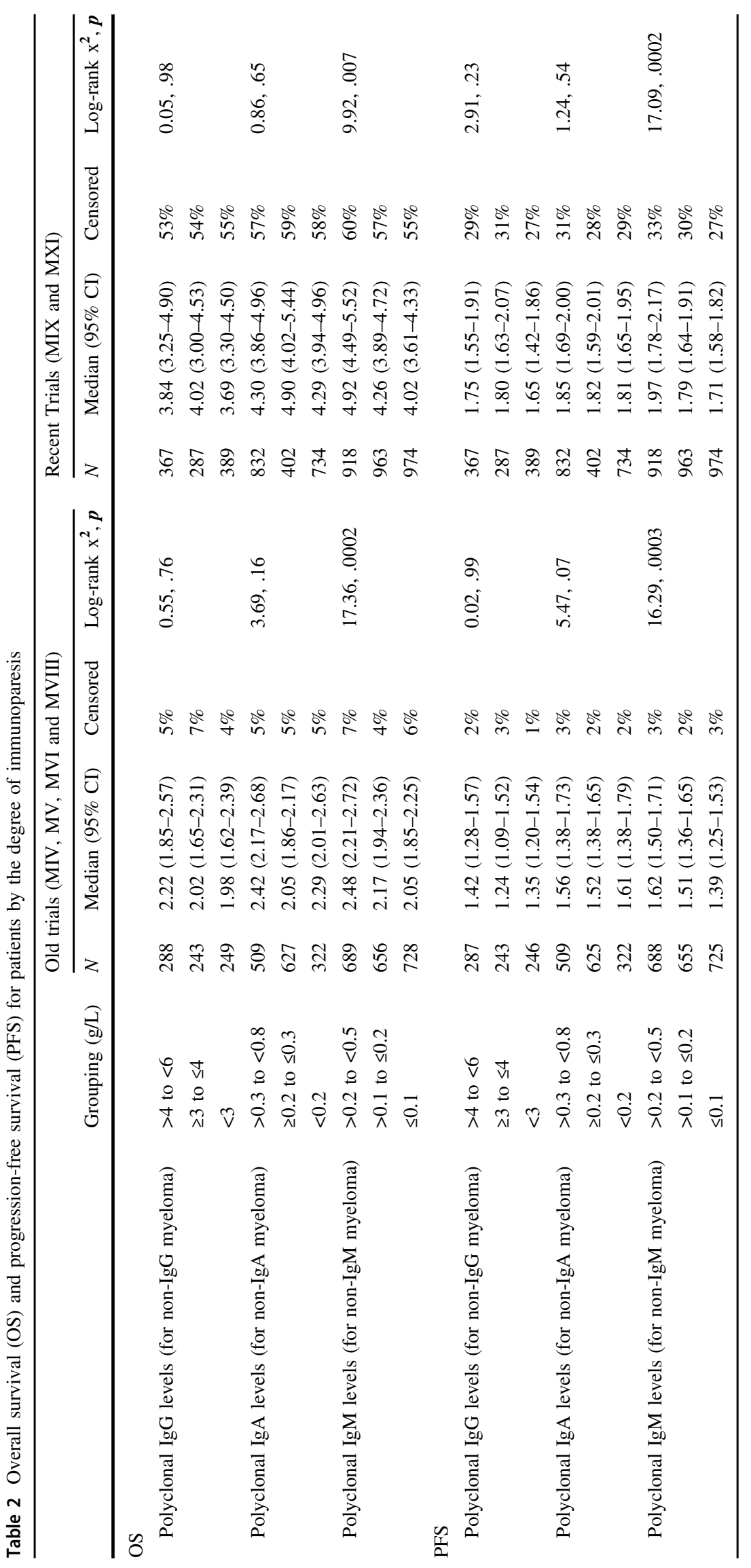



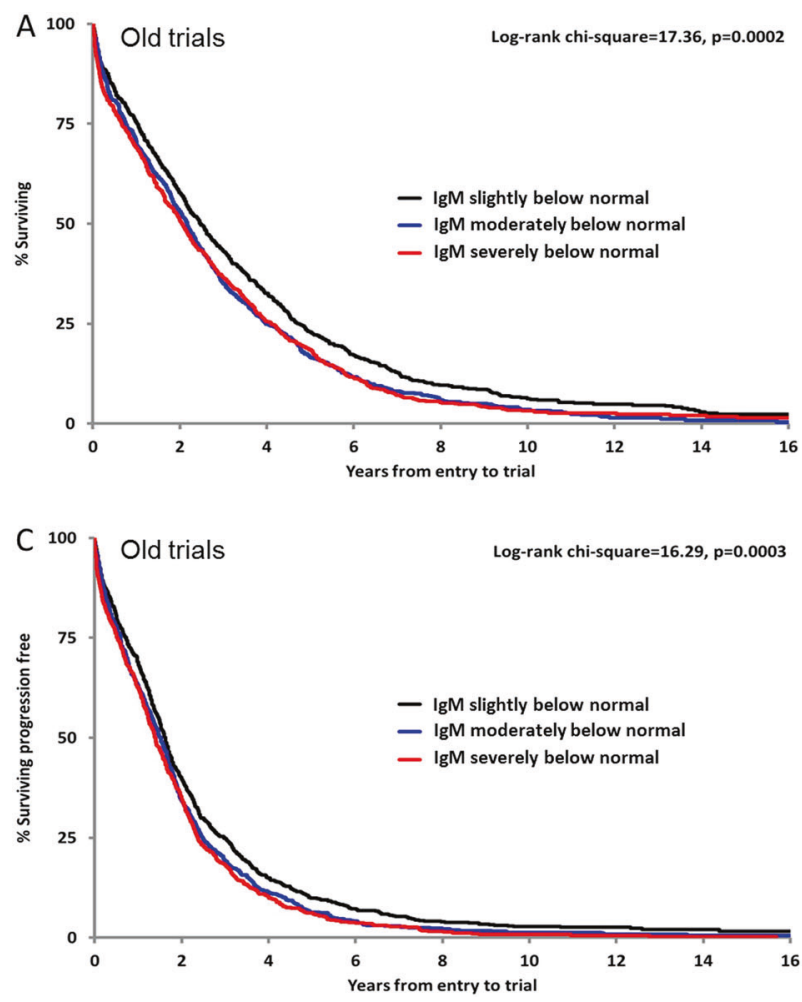

Fig. 3 Survival outcomes in relation to degree of IgM immunoparesis. Overall survival by degree of immunoparesis of polyclonal IgM levels for old trials (a) and recent MIX and MXI trials (b). Progression-free survival by degree of immunoparesis of polyclonal IgM levels presented for old trials (c) and recent MIX and MXI trials (d). Patients

respectively, despite a greater proportion of patients being older in the more recent trials. In both old and recent myeloma clinical trials, patients with immunoparesis at diagnosis had significantly poorer PFS and OS compared with patients for whom polyclonal immunoglobulin levels were within the NR $(p<0.01$ for all comparisons, Supplementary Table 2). The association of immunoparesis with poor survival was stronger in recent than old trials. In the old trials, individuals with normal levels of polyclonal $\mathrm{IgG}$ had a median OS that was $19 \%$ longer than the OS of individuals with low IgG; in the recent trials, this OS benefit for individuals with normal levels of polyclonal $\mathrm{IgG}$ at diagnosis was $80 \%$ longer than in those with immunoparesis. For polyclonal IgA levels, OS was $30 \%$ and $39 \%$ longer and for IgM 29\% and 50\% longer in old and recent trials, respectively.

In the recent trials, median OS (95\% CI), in years, for normal (19\% of patients) versus low ( $81 \%$ of patients) polyclonal IgG was 6.93 (CI $4.89-7.33$ ) and 3.84 (3.44-4.37), respectively; for normal (19\% of patients) versus low (81\% of patients) polyclonal IgA levels was 6.15 (5.21-7.33) and 4.42 (4.15-4.82), respectively; for normal (11\% of patients) versus low (89\% of patients) polyclonal IgM levels was $6.59(5.29-8.08)$ and 4.37
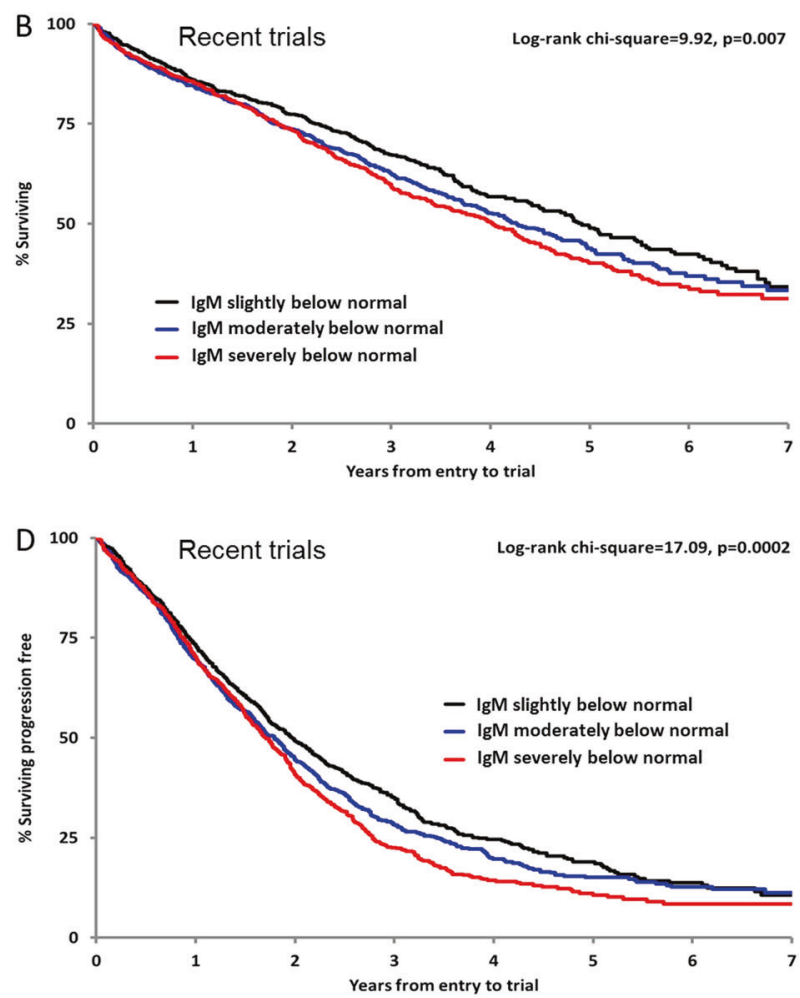

below the normal range for polyclonal $\operatorname{IgM}(<0.5 \mathrm{~g} / \mathrm{L})$ were divided into three tertiles based upon degree of suppression: slightly below normal $>0.2$ to $<0.5 \mathrm{~g} / \mathrm{L}$; moderately below normal $>0.1$ to $\leq 0.2 \mathrm{~g} / \mathrm{L}$; severely below normal $<0.1 \mathrm{~g} / \mathrm{L}$

(4.14-4.64), respectively (all $p<0.0003$; Supplementary Table 2). In the recent trials, median PFS, in years (95\% $\mathrm{CI}$ ), for normal versus low polyclonal IgG levels was 2.41 (1.96-3.12) and 1.73 (1.62-1.86), respectively; for normal versus low polyclonal $\operatorname{IgA}$ levels was 2.49 (2.03-2.79) and 1.83 (1.73-1.93), respectively; for normal versus low polyclonal IgM levels was 2.83 $(2.28-3.17)$ and $1.80(1.72-1.89)$, respectively (all $p<0.0001$; Supplementary Table 2).

Immunoparesis of the uninvolved sFLC (either kappa or lambda) did not impact upon OS or PFS; notably over twothirds of patients had polyclonal sFLC levels in the NR, which in part reflects the high prevalence of reduced glomerular filtration in myeloma, itself an adverse factor for survival (Supplementary Table 2).

\section{The depth of IgM suppression, but not the depth of $\lg$ G or IgA suppression, is a prognostic factor for survival outcomes}

In the recent MIX and MXI trials, median OS was 6.59 years in the 342 patients with normal polyclonal IgM levels at diagnosis and 4.37 years in the 2855 patients with IgM levels below the NR at diagnosis. Dividing these 2855 
Table 3 Cox regression table to predict overall survival (OS) and progression-free survival (PFS) from those enroled in MRC myeloma trials from 1980 to 1997 (old trials) compared to the MRC Myeloma IX trial (2003-2008) and the ongoing NCRI Myeloma XI trial (2010-2016)

\begin{tabular}{|c|c|c|c|c|c|c|c|c|c|}
\hline \multicolumn{5}{|c|}{ Old trials (MIV, MV, MVI and MVIII) } & \multicolumn{5}{|c|}{ Recent trials (MIX and MXI) } \\
\hline Factor & Grouping & $N$ & $\mathrm{HR}(95 \% \mathrm{CI})$ & $p$ & Factor & Grouping & $N$ & $\mathrm{HR}(95 \% \mathrm{CI})$ & $p$ \\
\hline \multicolumn{10}{|l|}{ OS } \\
\hline SB2M group & $\leq 4,4-8,>8$ & 1926 & $1.32(1.19-1.46)$ & $<.0001$ & SB2M group & $\leq 4,4-8,>8$ & 145 & $1.04(1.02,1.06)$ & .0002 \\
\hline Age group & $<65 \mathrm{yrs}, \geq 65 \mathrm{yrs}$ & & $1.25(1.14-1.38)$ & $<.0001$ & Age group & $<65 \mathrm{yrs}, \geq 65 \mathrm{yrs}$ & & $1.83(1.55,2.17)$ & $<.0001$ \\
\hline$\%$ BMPCs & $<20,20-50,>50$ & & $1.17(1.09-1.25)$ & $<.0001$ & $\%$ BMPCs & $<20,20-50,>50$ & & $1.10(0.98,1.23)$ & .11 \\
\hline ISS & I, II, III & & $1.18(1.05-1.32)$ & .005 & ISS & I, II, III & & $1.32(1.15,1.52)$ & $<.0001$ \\
\hline Polyclonal IgM & Continuous & & $0.89(0.77-1.03)$ & .12 & Polyclonal IgM & Continuous & & $0.64(0.42,0.97)$ & .04 \\
\hline \multirow[t]{2}{*}{ Sex } & Male, female & & $0.91(0.83-1.00)$ & .06 & Sex & Male, female & & $1.04(0.88,1.22)$ & .68 \\
\hline & & & & & Genetic risk & SR, HR & & $1.65(1.40,1.95)$ & $<.0001$ \\
\hline \multicolumn{10}{|l|}{ PFS } \\
\hline SB2M group & $\leq 4,4-8,>8$ & 1921 & $1.21(1.09-1.33)$ & .0002 & SB2M group & $\leq 4,4-8,>8$ & 1415 & $1.03(1.01,1.05)$ & .0002 \\
\hline Age group & $<65 \mathrm{yrs}, \geq 65 \mathrm{yrs}$ & & $1.13(1.03-1.24)$ & .01 & Age group & $<65 \mathrm{yrs}, \geq 65 \mathrm{yrs}$ & & $1.75(1.54,1.99)$ & $<.0001$ \\
\hline$\%$ BMPCs & $<20,20-50,>50$ & & $1.23(1.15-1.31)$ & $<.0001$ & $\%$ BMPCs & $<20,20-50,>50$ & & $1.05(0.96,1.28)$ & .33 \\
\hline ISS & I, II, III & & 1.19 (1.06-1.32) & .003 & ISS & I, II, III & & $1.16(1.15,1.51)$ & .005 \\
\hline Polyclonal IgM & Continuous & & $0.84(0.73-0.98)$ & .02 & Polyclonal IgM & Continuous & & $0.62(0.46,0.83)$ & .002 \\
\hline \multirow[t]{2}{*}{ Sex } & Male, female & & $0.91(0.83-0.99)$ & .04 & Sex & Male, female & & $1.13(0.99,1.28)$ & .07 \\
\hline & & & & & Genetic risk & SR, HR & & $1.39(1.22,1.58)$ & $<.0001$ \\
\hline
\end{tabular}

patients into tertiles, median OS in the lowest IgM tertile group was 4.02 years compared to 4.26 years in the middle group and 4.92 years in the tertile with the least severe immunoparesis ( $p=0.007$; Table 2 and Fig. 3). Examining the depth of immunoparesis by tertiles for polyclonal $\mathrm{IgG}$ and IgA levels at diagnosis showed no significant difference at $p=0.98$ and 0.65 , respectively. The same was found in the old trials, where the greater the depth of IgM immunoparesis, the shorter the median OS, whereas the depth of IgG or IgA immunoparesis was not associated with altered OS (Table 2).

In these recent trials, median PFS was 2.83 years in the 342 patients with normal polyclonal IgM levels at diagnosis and 1.80 years in the 2855 patients with IgM levels below the NR. Again, when dividing these 2855 patients into tertiles, median PFS in the lowest IgM tertile group was 1.71 years compared to 1.79 years in the middle group and 1.97 years in the tertile with the least severe immunoparesis ( $p=0.0002$; Table 2 and Fig. 3). Examining the depth of immunoparesis by tertiles for polyclonal IgG and IgA levels at diagnosis showed no significant difference for PFS ( $p=0.23$ and 0.54 , respectively). The same was found in the old trials, where the greater the depth of IgM immunoparesis, the shorter the median PFS was while depth of IgG or IgA immunoparesis was not associated with a difference in PFS (Table 2).

It is evident in the Kaplan-Meier curves in Fig. 3 that the survival advantages associated with higher levels of IgM only become apparent after the first year. Analysis of survival data up to 6 months has shown no difference in early deaths between immunoparesis groups. OS was $92 \%$ at 6 months for patients with IgM within the NR and $91 \%$ in patients with IgM below NR, log rank $p=0.65$. PFS was $89 \%$ within NR and $87 \%$ below NR, $p=0.21$.

Cox regression models were fitted to assess the independent effects of polyclonal IgM on OS and PFS after adjusting for known prognostic factors (age greater or less than 65 years, S $\beta 2$ M, BMPCs, ISS and sex) in the older trials with the addition of genetic risk for recent trials, Table 3 . These models confirmed polyclonal IgM as an independent prognostic factor of PFS in the old trials ( $\mathrm{HR}=0.84(95 \% \mathrm{CI}=$ $0.73-0.98), p=0.02$ ). Polyclonal IgM was confirmed to be an independent prognostic factor of OS and PFS in the recent trials $\mathrm{HR}=0.64(95 \% \mathrm{CI}=0.42-0.97, p=0.04)$ and 0.62 (95\% CI $=0.46-0.83, p=0.002$ ), respectively.

Polyclonal IgM suppression was shown to be an independent prognostic factor for both OS and PFS when controlling for SB2m, age, BMPCs, ISS, sex and genetic risk in recent trials ( $p=0.04$ and $p=0.002$, respectively, Table 3 ). For each point increase in polyclonal IgM, the hazard of death decreased by an estimated $36 \%$ and progression or death by an estimated $38 \%$. Within the old trials, IgM immunoparesis was found to be prognostic of PFS independent of S $\beta 2 \mathrm{M}$, age, BMPCs, ISS and sex, $p=0.02$.

\section{Discussion}

This study provides in-depth analysis of immunoparesis in newly diagnosed MM patients enroled into UK clinical 
trials. To our knowledge, this is the first study of this nature in a large cohort of patients enroled in national clinical trials. Findings exposed a notably high incidence of immunoparesis at diagnosis, where, in $80 \%$ of patients, polyclonal $\mathrm{IgG}$ and $\operatorname{IgA}$ immunoglobulin levels were below the NR, and for $89 \%$ of patients, polyclonal IgM levels were below the NR. The degree of immunoparesis was also severe, with median polyclonal values presenting substantially below the lower limit of the NRs. The distribution of polyclonal immunoglobulin levels observed in the present analysis also conveys a simple, yet important, clinical message in determining the diagnosis of MM versus other monoclonal gammopathies. If polyclonal immunoglobulins are above the NR, then the patient almost certainly does not have MM. This is supported by none of the 1302 patients without an IgG M-protein being above the NR for polyclonal IgG, and only $8 / 3226(0.2 \%)$ of patients exhibiting polyclonal IgM levels above NR.

The impact of intact M-protein type on immunoparesis has yielded conflicting findings in previous studies. One study of 940 patients found no significant differences between classes of M-protein [4], whereas another previous investigation of 1027 patients found uninvolved immunoglobulins were reduced in a higher proportion of $\operatorname{IgA}$ compared with IgG M-protein patients [2]. We have found the degree of immunoparesis was greatest in patients with $\operatorname{IgD}$ and IgA M-protein heavy chain types and with lambda light chain type, but these differences between M-protein types were not large. Similarly, there was a significant but not close association between M-protein levels and degree of immunoparesis. Importantly, LCO patients had severe immunoparesis, indicating that the mechanism of immunoparesis is not dependent on Fc regions of M-proteins.

In the present study, the presence of immunoparesis alone was associated with a negative effect on patient survival and disease control: for each point increase in IgM immunoglobulin levels decreased the risk of death by up to $36 \%$. This is consistent with a previous study, which found preservation of polyclonal immunoglobulins was associated with improved survival in 1755 patients and longer PFS in a smaller sub-cohort of 500 patients [18]. Although, in a more recent Danish multiple myeloma registry study, immunoparesis was associated with shorter PFS, while the shorter OS was not significant in multivariable analysis [31]. The present investigation confirms and extends these findings to a larger population of patients in the context of national clinical trials.

We compared the impact of immunoparesis on survival outcomes in different eras of therapy through assessment of both historical (2608 patients) and recent UK clinical trials (3218 patients). Despite a greater proportion of patients being aged $\geq 65$ years in the more recent MIX and MXI trials, adding predominantly thalidomide or lenalidomide with dexamethasone, patients lived twice as long as the patients from the old trials. This re-confirms the superior efficacy of current anti-myeloma therapies. Importantly, this study highlights preservation of polyclonal immunoglobulin levels of $\mathrm{G}, \mathrm{A}$ or $\mathrm{M}$ class at diagnosis, as a key prognostic factor for OS and PFS in older trials irrespective of age $<65$ yrs $/ \geq 65$ yrs and with an even more profound effect in recent trials employing modern therapy in both intensive and nonintensive pathways. From old to recent trials, survival has doubled for all patients but the differences in median overall survival times between patients within or below the NR were more pronounced for the new trials (up to 3 years) compared to the old trials (less than 1 year). For patients with normal versus reduced IgM levels, median OS was longer by $29 \%$ in old trials and $51 \%$ in new trials. Similarly, PFS was longer by $25 \%$ in old and $57 \%$ in recent trials. This reveals that improved survival from modern therapies has been greatest in patients without severe immunoparesis and that the mechanism of immunoparesis may be an important new therapeutic target.

Over two-thirds of patients had normal levels of polyclonal free light chains and this was not associated with better survival probably because the normal levels were more often the result of reduced glomerular filtration rather than preservation of secretion; $45 \%$ of patients had an eGFR $<60 \mathrm{mls} / \mathrm{min}$. In recent trials comparing patients with normal polyclonal levels with patients with levels below the NR, median OS and median PFS were significantly longer for patients with normal IgG, IgA or IgM levels. However, only a small proportion of patients had normal immunoglobulin levels $(\leq 20 \%)$ and so it was important to see the effect on survival of depth of suppression of polyclonal immunoglobulin levels below the NR. Depth of suppression of polyclonal $\mathrm{IgG}$ or $\operatorname{IgA}$ levels below the NR was not associated with worse PFS or OS. In contrast, the degree of suppression of polyclonal IgM levels below the NR was significantly associated with survival. In recent trials, the most severely suppressed tertile of patients OS was 0.9 years $(18 \%)$ shorter than those in the top tertile and 2.57 years $(39 \%)$ shorter than OS of those with IgM levels within the NR. Similarly, the degree of suppression of polyclonal IgM levels below the NR was significantly associated with worse PFS. The most severely suppressed tertile of patients PFS was 0.26 years $(13 \%)$ shorter than those in the top tertile and 1.12 years $(40 \%)$ shorter than PFS of those with IgM levels within the NR.

IgM antibodies are the first class of antibodies produced following antigen exposure, offering early protection against microbial infection and are derived predominantly from secondary lymphoid tissues, not the bone marrow [32]. Consequently, a reduced IgM level in newly diagnosed MM patients has implications for primary antibody response, vaccination efficacy and risk of infection. 
However, reduced secretion of polyclonal IgM from plasma cells distant from bone marrow also highlights the question of mechanism of immunosuppression and the hypothesis that it might be associated with aggressive MM and reduced immune surveillance of MM.

Infection reaps the greatest toll in mortality in the early months from diagnosis during active disease and we are currently investigating the complexity of that innate and specific immunosuppression in the TEAMM trial that has compared prophylactic levofloxacin antibiotic prophylaxis with placebo. It is clear from the survival curves in Fig. 3 that IgM immunoparesis had little effect on survival during this period while it had a profound effect on overall survival in both old and modern trials. The effect on PFS, in which infection is unlikely to play a major part, is even more interesting. The level of IgM immunoparesis may reflect disease activity/severity and therefore the depth of $\operatorname{IgM}$ suppression may be a proxy marker of inherent malignancy and possible resistance to therapy. The mediating factors between low IgM levels and risk of death/disease progression require further investigation and future studies may seek to identify the underlying mechanisms between immunoparesis and patient outcomes. A recent study found recovery of polyclonal immunoglobulins 1 year after autologous stem cell transplantation predicts progression-free and overall survival [33]. Subsequent studies should consider the relative importance of immunoparesis at diagnosis versus post therapy in relation to long-term outcomes.

\section{Conclusion}

The results from this large data set of newly diagnosed MM patients provide a comprehensive up-to-date characterisation of immunoparesis at diagnosis and demonstrate the strong prognostic significance for both progression-free survival and overall survival in historical trials and even more profoundly in present-day clinical trials featuring modern anti-myeloma therapy. In contrast to polyclonal $\mathrm{IgG}$ and $\operatorname{IgA}$, it is not simply the presence of immunoparesis but for polyclonal IgM also its severity that predicts patient survival. Immunoparesis is generally thought to reduce survival by increased infection rates but this does not seem to be the predominant mechanism. There is little impact of immunoparesis in the first 6 months from diagnosis the time at which infection is most common. Further immunoparesis profoundly reduces PFS that in itself is little dependent upon infection rates. We hypothesise that IgM immunoparesis impacts survival through a combination of being associated with more aggressive disease and reduced immune surveillance. This impact is much greater in recent trials revealing that improved survival from modern therapies has been greatest in patients without severe immunoparesis and that the mechanism of immunoparesis may be an important new therapeutic target.

Acknowledgements We are grateful to the NCRI Haemato-oncology subgroup and to all principal investigators for their dedication and commitment to recruiting patients to Myeloma IX and XI. We thank the Clinical Trials Research Unit at The University of Leeds (Myeloma IX and XI). We are grateful to the staff of the Clinical Immunology Service in Birmingham with Tim Plant, Karen Walker, Alison Adkins and Nicola Newnham. Finally, we are grateful to all patients and their clinical teams at centres throughout the UK whose participation made this study possible.

Author contributions $\mathrm{JH}, \mathrm{JC}$ and $\mathrm{MD}$ wrote the first draft of the manuscript. JAC, GM and GJ were the chief investigators on myeloma IX and XI trials. DC and WG are statisticians and FD haematologist on myeloma IX and XI trials. JLH, JC, MD, GI and JD gathered, analysed and interpreted the data. All authors provided changes to the first draft of the manuscript and approved the final manuscript.

Conflict of interest MTD reports personal fees and other from Abingdon Health, outside the submitted work. JPC reports other from Abingdon Health, outside the submitted work. GM reports personal fees from Amgen, Celgene, Janssen and Takeda, outside the submitted work. The remaining authors declare no competing interests.

Open Access This article is licensed under a Creative Commons Attribution 4.0 International License, which permits use, sharing, adaptation, distribution and reproduction in any medium or format, as long as you give appropriate credit to the original author(s) and the source, provide a link to the Creative Commons license, and indicate if changes were made. The images or other third party material in this article are included in the article's Creative Commons license, unless indicated otherwise in a credit line to the material. If material is not included in the article's Creative Commons license and your intended use is not permitted by statutory regulation or exceeds the permitted use, you will need to obtain permission directly from the copyright holder. To view a copy of this license, visit http://creativecommons. org/licenses/by/4.0/.

\section{References}

1. Dimopoulos MA, Kastritis E, Anagnostopoulos A. Hematological malignancies: myeloma. Ann Oncol. 2006;17:x137-43.

2. Kyle RA, Gertz MA, Witzig TE, Lust JA, Lacy MQ, Dispenzieri A, et al. Review of 1027 patients with newly diagnosed multiple myeloma. Mayo Clin Proc. 2003;78:21-33.

3. Wangel A. Multiple myeloma and polyclonal hypogammaglobulinaemia. Acta Med Scand. 1987;221:421-5.

4. Pruzanski W, Gidon MS, Roy A. Suppression of polyclonal immunoglobulins in multiple myeloma: relationship to the staging and other manifestations at diagnosis. Clin Immunol Immunopathol. 1980;17:280-6.

5. Wang L, Young DC. Suppression of polyclonal immunoglobulin production by M-proteins shows isotype specificity. Ann Clin Lab Sci. 2001;31:274-8.

6. Alexanian R, Migliore PJ. Normal immunoglobulins in multiple myeloma: effect of melphalan chemotherapy. J Lab Clin Med. 1970;75:225-33.

7. Kawano M, Iwato K, Asaoku H, Tanabe O, Tanaka H, Ishikawa $\mathrm{H}$, et al. Altered cytokine activities are related to the suppression of synthesis of normal immunoglobulin in multiple myeloma. Am J Hematol. 1989;30:91-6.

8. Peltonen S, Wasastjerna C, Wager O. Clinical features of patients with a serum M component. Acta Med Scand. 1978;203:257-63. 
9. Nucci M, Anaissie E. Infections in patients with multiple myeloma in the era of high-dose therapy and novel agents. Clin Infect Dis. 2009;49:1211-25.

10. Hargreaves RM, Lea JR, Griffiths H, Faux JA, Holt JM, Reid C, et al. Immunological factors and risk of infection in plateau phase myeloma. J Clin Pathol. 1995;48:260-6.

11. Blimark C, Holmberg E, Mellqvist UH, Landgren O, Bjorkholm M, Hultcrantz M, et al. Multiple myeloma and infections: a population-based study on 9253 multiple myeloma patients. Haematologica. 2015;100:107-13.

12. Pratt G, Goodyear O, Moss P. Immunodeficiency and immunotherapy in multiple myeloma. Br J Haematol. 2007;138:563-79.

13. Augustson BM, Begum G, Dunn JA, Barth NJ, Davies F, Morgan $\mathrm{G}$, et al. Early mortality after diagnosis of multiple myeloma: analysis of patients entered onto the United Kingdom Medical Research Council trials between 1980 and 2002-Medical Research Council Adult Leukaemia Working Party. J Clin Oncol. 2005;23:9219-26.

14. Perez-Persona E, Vidriales MB, Mateo G, Garcia-Sanz R, Mateos MV, de Coca AG, et al. New criteria to identify risk of progression in monoclonal gammopathy of uncertain significance and smoldering multiple myeloma based on multiparameter flow cytometry analysis of bone marrow plasma cells. Blood. 2007;110:2586-92.

15. Turesson I, Kovalchik SA, Pfeiffer RM, Kristinsson SY, Goldin LR, Drayson MT, et al. Monoclonal gammopathy of undetermined significance and risk of lymphoid and myeloid malignancies: 728 cases followed up to 30 years in Sweden. Blood. 2014;123:338-45.

16. Rajkumar SV, Landgren O, Mateos MV. Smoldering multiple myeloma. Blood. 2015;125:3069-75.

17. Sorrig R, Klausen TW, Salomo M, Vangsted AJ, Ostergaard B, Gregersen $\mathrm{H}$, et al. Smoldering multiple myeloma risk factors for progression: a Danish population-based cohort study. Eur J Haematol. 2016;97:303-9.

18. Kastritis E, Zagouri F, Symeonidis A, Roussou M, Sioni A, Pouli A, et al. Preserved levels of uninvolved immunoglobulins are independently associated with favorable outcome in patients with symptomatic multiple myeloma. Leukemia. 2014;18:110.

19. Morgan GJ, Davies FE, Gregory WM, Cocks K, Bell SE, Szubert AJ, et al. First-line treatment with zoledronic acid as compared with clodronic acid in multiple myeloma (MRC Myeloma IX): a randomised controlled trial. Lancet. 2010;376:1989-99.

20. Morgan GJ, Davies FE, Gregory WM, Russell NH, Bell SE, Szubert AJ, et al. Cyclophosphamide, thalidomide, and dexamethasone (CTD) as initial therapy for patients with multiple myeloma unsuitable for autologous transplantation. Blood. 2011;118:1231-8.

21. Morgan GJ, Davies FE, Gregory WM, Bell SE, Szubert AJ, Navarro Coy N, et al. Cyclophosphamide, thalidomide, and dexamethasone as induction therapy for newly diagnosed multiple myeloma patients destined for autologous stem-cell transplantation: MRC Myeloma IX randomized trial results. Haematologica. 2012;97:442-50.

22. Morgan GJ, Gregory WM, Davies FE, Bell SE, Szubert AJ, Brown JM, et al. The role of maintenance thalidomide therapy in multiple myeloma: MRC Myeloma IX results and meta-analysis. Blood. 2012;119:7-15.

23. Drayson M, Begum G, Basu S, Makkuni S, Dunn J, Barth N, et al. Effects of paraprotein heavy and light chain types and free light chain load on survival in myeloma: an analysis of patients receiving conventional-dose chemotherapy in Medical Research Council UK multiple myeloma trials. Blood. 2006;108:2013-9.

24. Katzmann JA, Clark RJ, Abraham RS, Bryant S, Lymp JF, Bradwell AR, et al. Serum reference intervals and diagnostic ranges for free kappa and free lambda immunoglobulin light chains: relative sensitivity for detection of monoclonal light chains. Clin Chem. 2002;48:1437-44.

25. Sonneveld P, Avet-Loiseau H, Lonial S, Usmani S, Siegel D, Anderson KC, et al. Treatment of multiple myeloma with highrisk cytogenetics: a consensus of the International Myeloma Working Group. Blood. 2016;127:2955-62.

26. Kaplan M, Meier P. Non parametric estimation from incomplete observations. J Stat Assoc. 1958;53:457-81.

27. Peto R, Pike MC, Armitage P, Breslow NE, Cox DR, Howard SV, et al. Design and analysis of randomized clinical trials requiring prolonged observation of each patient. II. analysis and examples. Br J Cancer. 1977;35:1-39.

28. Rajkumar SV, Harousseau JL, Durie B, Anderson KC, Dimopoulos M, Kyle R, et al. Consensus recommendations for the uniform reporting of clinical trials: report of the International Myeloma Workshop Consensus Panel 1. Blood. 2011;117:4691-5.

29. Cox RD. Regression models and life-tables. J R Stat Soc Ser B. 1972;34:187-220.

30. Campbell JP, Cobbold M, Wang Y, Goodall M, Bonney SL, Chamba A, et al. Development of a highly-sensitive multi-plex assay using monoclonal antibodies for the simultaneous measurement of kappa and lambda immunoglobulin free light chains in serum and urine. J Immunol Methods. 2013;391:1-13.

31. Sorrig R, Klausen TW, Salomo M, Vangsted AJ, Frolund UC, Andersen KT, et al. Immunoparesis in newly diagnosed multiple myeloma patients: effects on overall survival and progression free survival in the Danish population. PLoS ONE. 2017;12:e0188988.

32. Boes M. Role of natural and immune IgM antibodies in immune responses. Mol Immunol. 2000;37:1141-9.

33. Gonzalez-Calle V, Cerda S, Labrador J, Sobejano E, GonzalezMena B, Aguilera C, et al. Recovery of polyclonal immunoglobulins one year after autologous stem cell transplantation as a long-term predictor marker of progression and survival in multiple myeloma. Haematologica. 2017;102:922-31. 